\title{
First Characterization with Ultrasound Contrast Agent of a Fibrovascular Polyp Before Its Endoscopic Resection: A Case Report (with Videos)
}

\author{
Nicolas Williet ${ }^{1}$, Radwan Kassir ${ }^{2}$, Francois Casteillo ${ }^{3}$, Violaine Yvorel $^{3}$, Cyril Habougit ${ }^{3}$, Xavier Roblin ${ }^{1}$ and Jean-Marc Phelip ${ }^{1}$ \\ Department of ${ }^{1}$ Hepatogastroenterology, ${ }^{2}$ General Surgery, ${ }^{3}$ Pathology, University Hospital of Saint-Etienne, Saint-Priest en Jarez, France
}

We described for the first time the contrast enhancement of a giant fibrovascular esophageal polyp using ultrasound contrast agent, Sonovue $^{\mathbb{B}}$ (Bracco, Milan, Italy) during echoendoscopy. Fine Doppler was unsuccessful in showing vascularization due to the mobile characteristic of the tumor. In contrast, via Sonovue ${ }^{\circledR}$, tissue microcirculation was highlighted inside the entire head of the polyp, leading to better appreciate the risk of bleeding related to its resection. In a second part, we showed the feasibility of classic polypectomy for this giant polyp $(5 \times 5 \mathrm{~cm})$ without complication and results of control endoscopy at 3 months. The present case is summarized in a video. Clin Endosc 2019;52:186-190

Key Words: Esophageal fibrovascular polyp; Ultrasound endoscopy contrast enhancement; Polypectomy; Microvascularization

\section{INTRODUCTION}

Fibrovascular esophageal polyps are known to be richly vascularized, wherein echoendoscopy is recommended by some authors who described its resection. Overall, this occurrence of submucosal tumor is very rare, and there is no consensus on how to perform its resection that is classically with surgery. The use of ultrasound enhancement agent is well validated for the characterization of pancreatic cancer, ${ }^{1-5}$ and increasing data are available for submucosal tumors of the upper digestive tract, which is largely dominated by leimyoma and gastro-intestinal stromal tumor. ${ }^{6,7}$

Received: May 18, 2018 Revised: July 7, 2018

Accepted: July 25, 2018

Correspondence: Nicolas Williet

Department of Hepatogastroenterology, University Hospital of Saint-Etienne, Avenue Albert Raimond, Saint-Priest en-Jarez 42270, France

Tel: +336-65-24-29-40, Fax: +334-77-82-84-52, E-mail: nwilliet@yahoo.fr ORCID: https://orcid.org/0000-0002-7296-5464

cc This is an Open Access article distributed under the terms of the Creative Commons Attribution Non-Commercial License (http://creativecommons.org/ licenses/by-nc/3.0) which permits unrestricted non-commercial use, distribution, and reproduction in any medium, provided the original work is properly cited.

\section{CASE REPORT}

On December 2016, an esophageal tumor was incidentally found during positron emission tomography scanning (PET scan) (Fig. 1), which was performed annually in an asymptomatic 67-year-old man with a history of lymphoma since 2015. There was no local glucose metabolism, and the hypothesis of a benign origin was raised. Retrospectively, this tumor had been yet visible at previous PET scans. Endoscopically, the tumor appeared like a pedunculated submucosal polyp developing from the cervical esophageal-mouth, with a 50$\mathrm{mm}$ head and a 50-mm long thin peduncle (Fig. 2, Video 1). The scope could pass easily without any evidence of obstruction. The diagnosis of fibrovascular polyp was yet suspected at this time of investigation. Because this kind of tumors have been described as richly vascularized, ultrasound endoscopy was performed in the same operative time with pretherapeutic appraisal intent. The tumor developed under the mucosal layer that encompassed a homogenous hypoechogenic circular infiltration of the submucosa. The peduncle seemed to be tumor-free. The mobile characteristic of the tumor made the examination with fine Doppler sensitive. Hence, no vessel in 


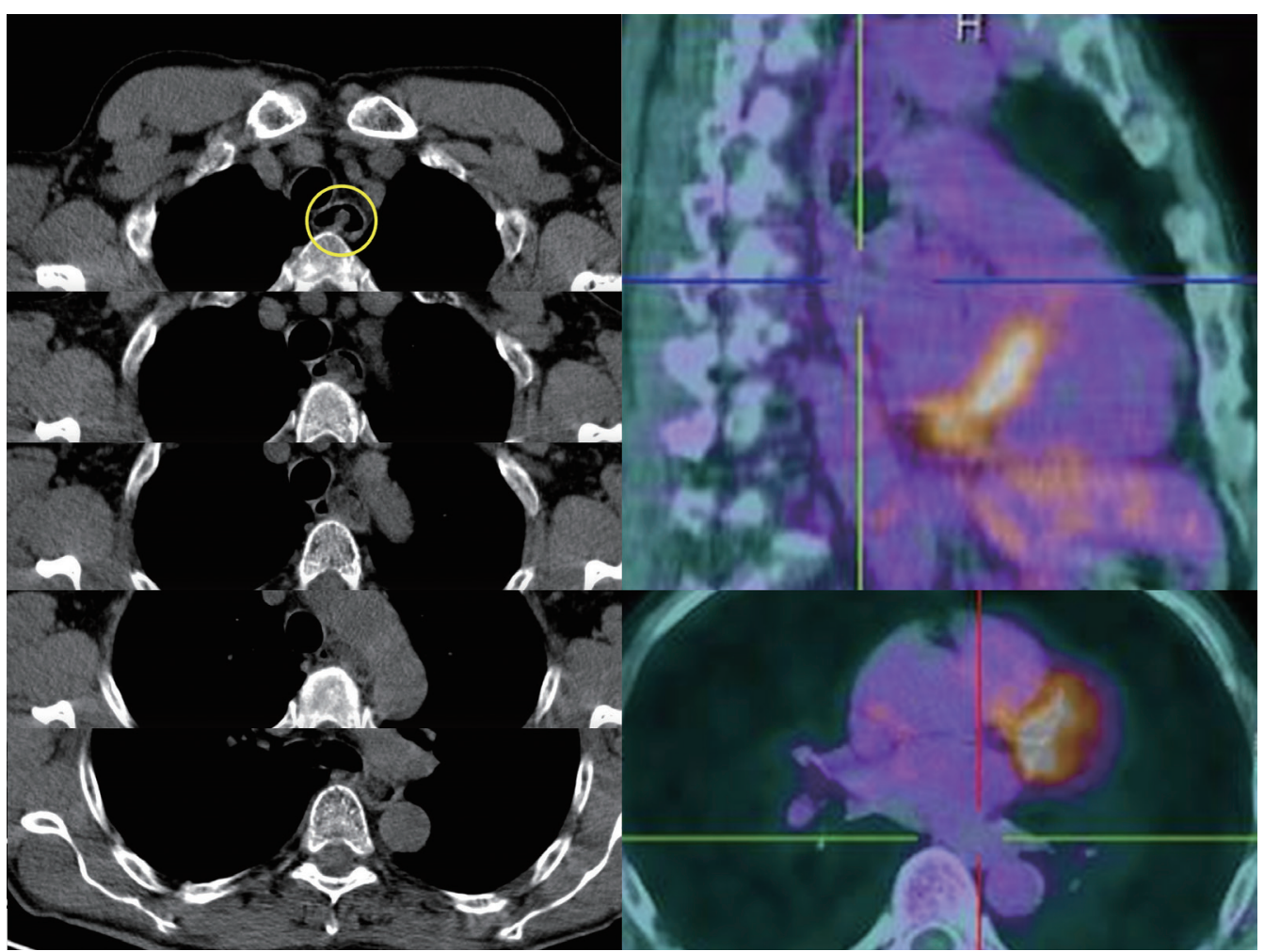

Fig. 1. Positron emission tomography scanning incidentally showing a non-local glucose metabolic esophageal tumor extended from the cervical esophagealmouth to the lower esophageal area.

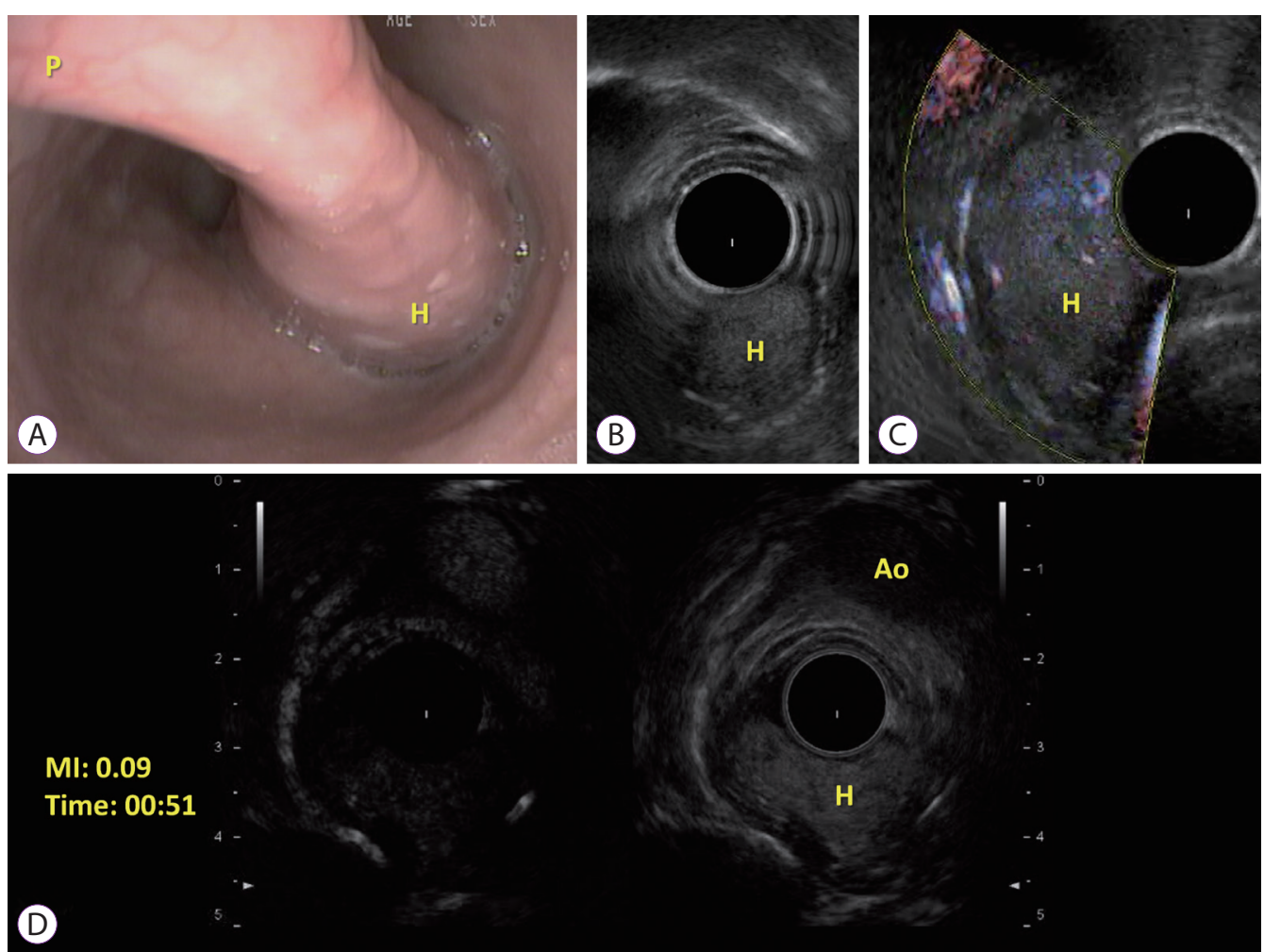

Fig. 2. (A) Endoscopic view of the esophageal fibrovascular polyp. Long thin peduncle $(P)$ and the head $(H)$ of the polyp; $(B)$ Ultrasound endoscopy imaging of the head $(\mathrm{H})$ of the polyp; $(\mathrm{C})$ Idem B with Fine doppler; (D) Contrast-enhanced endoscopic ultrasound of the head $(\mathrm{H})$ of the polyp at the same plane of the aorta (Ao), with low mechanical index (MI). 
either the head or peduncle of the polyp was shown by this method. An ultrasound contrast agent, Sonovue ${ }^{\circledR}$ (Bracco, Milan, Italy) was used to assess tissue microcirculation. With a low mechanical index, an intense homogeneous contrast enhancement was observed within the head of the tumor, starting at $25 \mathrm{~s}$ of infusion and maintained durably for $>2 \mathrm{~min}$. The intensity of this enhancement was relatively comparable as aorta that was seen in the same echographic plan. Microcirculation was particularly well visible through the microbubble movement (Fig. 2). Polyp resection was indicated to prevent aspiration. The endoscopic resection was performed twice (Fig. 3, Video 2) after obtaining the patient's consent. We chose to start by applying a large clip INSTINCT (Cook Medical Inc., Winston-Salem, NC, USA) at the base of the polyp to prevent bleeding and to maintain the remaining pedunculated mucosae closed. Adrenalin was injected in the downstream part of the peduncle before its coagulation $(30 \mathrm{~W})$ and resection (Endocut Q effect 5) by using a 30-mm snare. Neither early nor late complication occurred. Histopathological examination showed a well-differentiated adipose tumor with a superficial network of small vessels, that raises a hypothesis of a lipoma or an atypical lipoma (Fig. 4). Neither mitotic figure nor necrosis or infiltration of surrounding tissue was present. Degenerative cyto-nuclear atypias were present. There was no
MDM2 amplification (ZytoLight SPEC MDM2/CEN 12 Dual Color Probe; CliniSciences, Nanterre, France) by fluorescence in situ hybridization, which excludes an atypical lipoma. Numerous dilated vessels were present under the surface epithelium, explaining the intense enhancement with the contrast agent. After three months, control endoscopy showed the remaining peduncle without the clip.

\section{DISCUSSION}

Fibrovascular esophageal polyps, also previously called pedunculated lipoma, myxofibroma, and fibroma, are formed by a mucosal invagination. The food bolus elongates this polypoid lesion that gradually becomes pedunculated over time and develops vascularization along its axis with stroma and adipocytes. Hence, the peduncle of the polyp does not contain the deeper muscular layer of the esophagus, and endoscopic resection can be proposed with very limited risk of perforation. The risk of bleeding is more debatable, and some authors recommended that polyps $>80 \mathrm{~mm}$ should not be treated endoscopically. ${ }^{8,9}$ However esophageal surgery is known to be complex, associated with morbidity, and not always technically feasible. In the present case, the peduncle was thin,
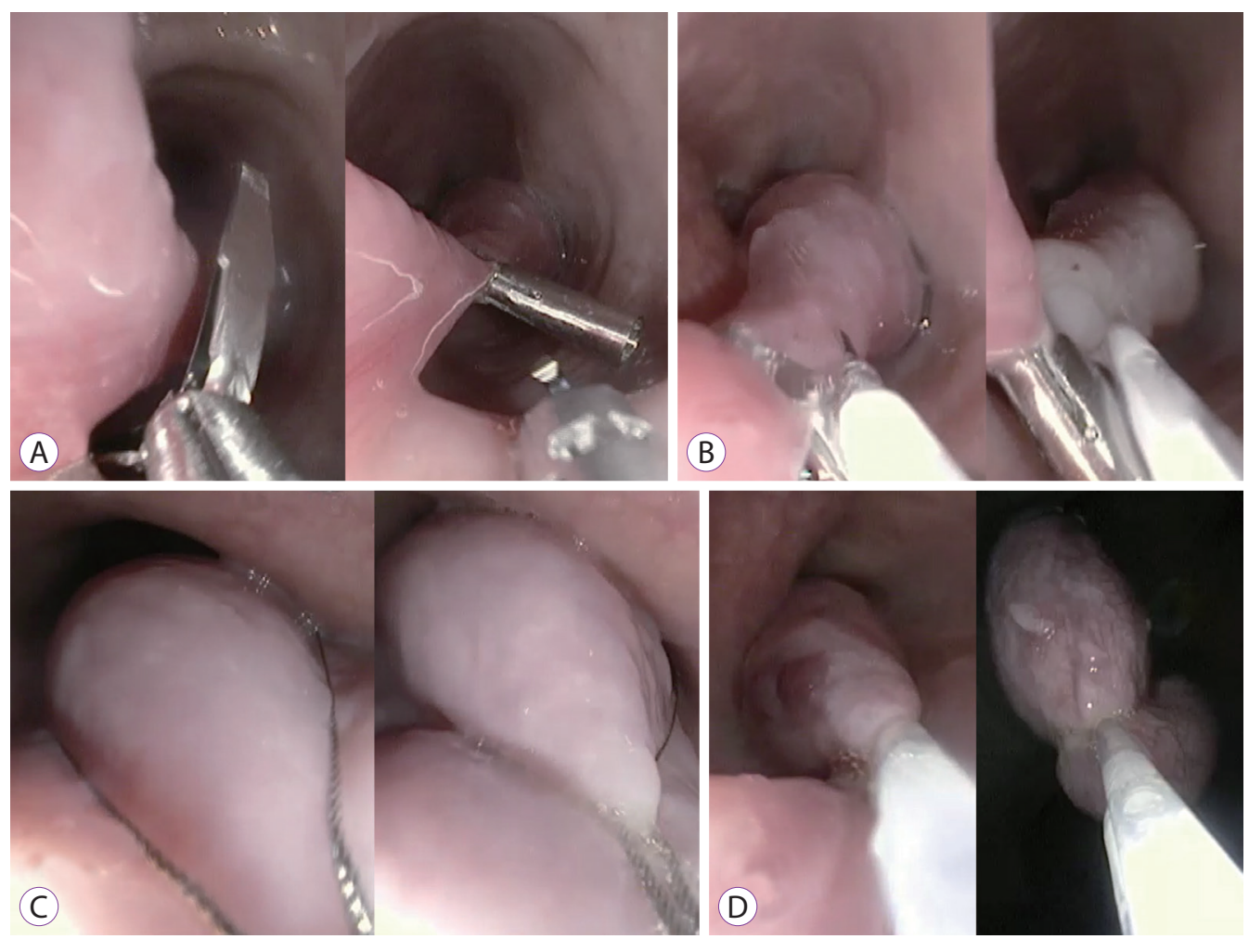

Fig. 3. Steps of fibrovascular polyp resection. (A) Applying a large clip; (B) adrenaline injection; (C) polyp catching with a 30-mm snare; (D) Peduncle coagulation by snare before cutting. 

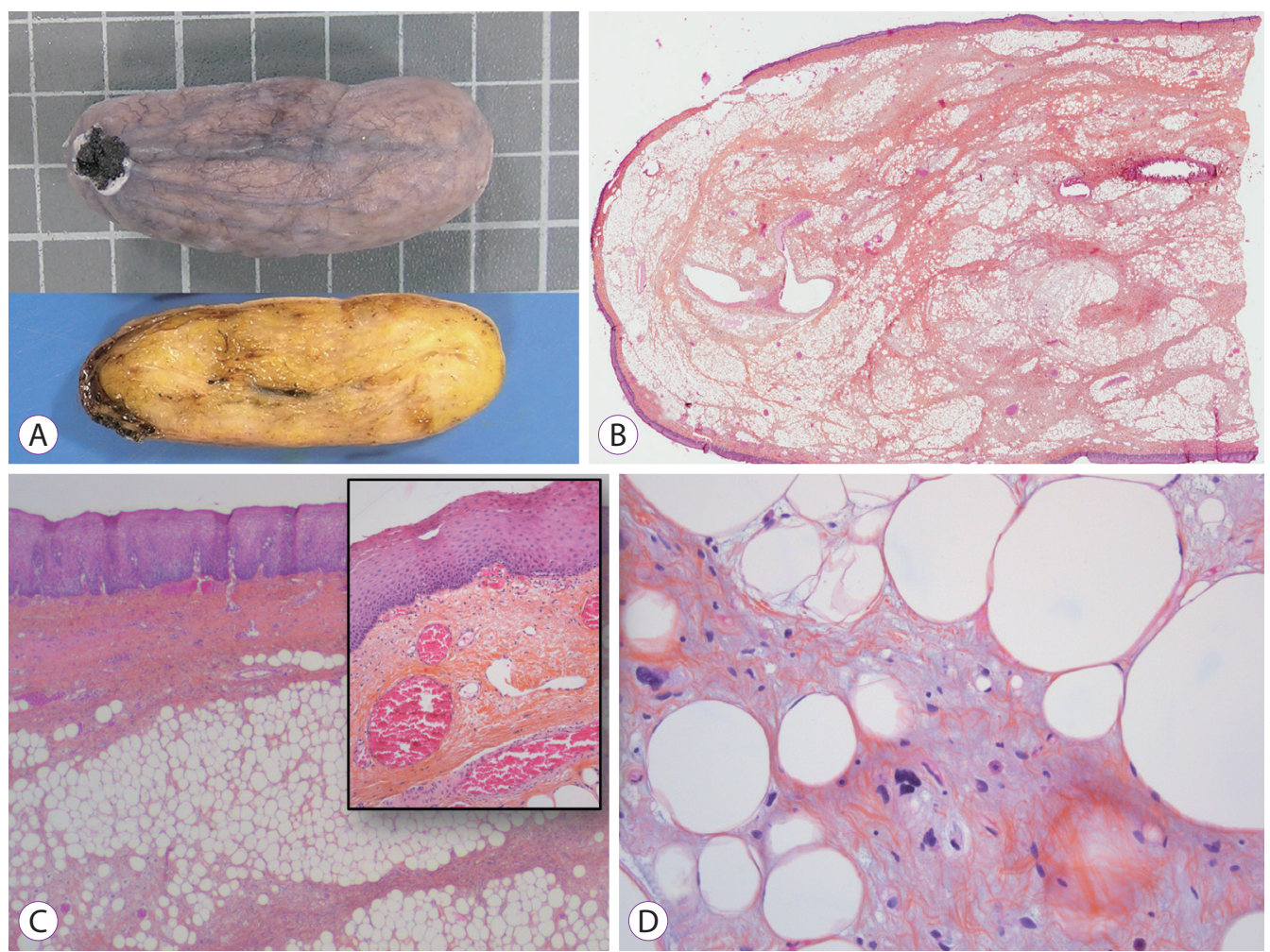

Fig. 4. (A) Upper: gross external aspect (square=1 cm), Lower: cut surface showing homogeneous yellowish color. (B) Low magnification view showing a central fibrous and adipose core surrounded by squamous epithelium, hematoxylin and eosin $(H \& E), \times 1$. (C) Squamous epithelium covering the entire surface with dilated vessels below the epithelium, $\mathrm{H \& E}, \times 100$ (inlay, $\mathrm{H \& E}, \times 200$ ). (D) Degenerative atypias of adipocytes, $\mathrm{H} \& \mathrm{E}, \times 400$.

and bleeding was prevented by large clip application, adrenalin injection, and long-term coagulation with snare before resection. Vascularization was not detected by fine Doppler. Although not indispensable in the present case before polyp resection, Sonovue ${ }^{\circledR}$, as enhancement contrast agent, confirmed its efficacy in identifying microvascularization and improving characterization of a submucosal tumor of the upper digestive tract. The mobile characteristic of the tumor made the examination with fine Doppler sensitive, and hence the use of Sonovue ${ }^{\circledR}$ was relatively helpful in this case to confirm the absence of macrovessels. To the best of our knowledge, this is the first study on characterization with contrast agent ultrasound reported in the literature for this rare submucosal tumor. We chose to perform a standard polypectomy because this method seemed to be simplest and feasible in the present case. However, other methods, such as endoscopic submucosal dissection had been yet described for this kind of tumor. ${ }^{10}$

\section{Conflicts of Interest}

The authors have no financial conflicts of interest.

\section{Supplementary Material}

Video 1. Characterization of the fibrovascular esophageal polyp by mode B echoendoscopy, fine Doppler and ultrasound enhancement (https://doi. org/10.5946/ce.2018.083.v001).

Video 2. Polypectomy of the giant fibrovascular esophageal lesion after preventive hemostatic measures (https://doi.org/10.5946/ce.2018.083.v002).

\section{REFERENCES}

1. Kitano M, Kudo M, Yamao K, et al. Characterization of small solid tumors in the pancreas: the value of contrast-enhanced harmonic endoscopic ultrasonography. Am J Gastroenterol 2012;107:303-310.

2. Fusaroli P, Spada A, Mancino MG, Caletti G. Contrast harmonic echo-endoscopic ultrasound improves accuracy in diagnosis of solid pancreatic masses. Clin Gastroenterol Hepatol 2010;8:629-634.e1-e2.

3. Fusaroli P, Eloubeidi MA. Diagnosis of pancreatic cancer by contrast-harmonic endoscopic ultrasound (EUS): complementary and not competitive with EUS-guided fine-needle aspiration. Endoscopy 2014;46:380-381.

4. Gincul R, Palazzo M, Pujol B, et al. Contrast-harmonic endoscopic ultrasound for the diagnosis of pancreatic adenocarcinoma: a prospective multicenter trial. Endoscopy 2014;46:373-379.

5. Claudon M, Cosgrove D, Albrecht T, et al. Guidelines and good clinical practice recommendations for contrast enhanced ultrasound (CEUS) update 2008. Ultraschall Med 2008;29:28-44.

6. Kannengiesser K, Mahlke R, Petersen F, et al. Contrast-enhanced harmonic endoscopic ultrasound is able to discriminate benign submucosal lesions from gastrointestinal stromal tumors. Scand J Gastroenterol 2012;47:1515-1520.

7. Fusaroli P, Kypraios D, Mancino MG, et al. Interobserver agreement in contrast harmonic endoscopic ultrasound. J Gastroenterol Hepatol 


\section{$C_{\text {clinical endoscopy }}$}

2012;27:1063-1069.

8. Park JS, Bang BW, Shin J, et al. A case of esophageal fibrovascular polyp that induced asphyxia during sleep. Clin Endosc 2014;47:101-103.

9. Lee SY, Chan WH, Sivanandan R, Lim DT, Wong WK. Recurrent giant fibrovascular polyp of the esophagus. World J Gastroenterol
2009;15:3697-3700.

10. Lorenzo D, Gonzalez JM, Barthet M. Endoscopic resection of a giant esophageal fibrovascular polyp. Endoscopy 2016;48 Suppl 1 UCT$\mathrm{N}$ :E69-E70. 